the prescription to put Mr Kozary on his guard. Dr Miller's negligence had contributed to the negligence of $\mathrm{Mr}$ Kozary, although the greater proportion of the responsibility lay with $\mathrm{Mr}$ Kozary.

Accordingly, Mr Justice Auld awarded damages of $£ 119302$ plus interest against Mr Kozary, his pharmacy, and Dr Miller, the proper apportionment of which was that $\mathrm{Dr}$ Miller was $25 \%$ liable and $\mathrm{Mr}$ Kozary $75 \%$ liable.

\section{The implications}

Though the implications of the decision in these cases may seem obvious from the facts, their seriousness should not be underestimated by those in the medical and pharmaceutical professions. What is clear from the decision in Prendergast is that doctors are under a legal duty of care to write clearly - that is, with sufficient legibility to allow for mistakes by others. Both Prendergast and Dwyer show that liability need not stop when the prescription leaves the hands of the doctor, even when the doctor has been grossly negligent. It may extend into and be a cause of the negligent mistakes of others.
The pharmacist must be aware that he or she must not tacitly accept what they see, or perceive to see, on the written prescription before them. They are under a legal duty of care to draw on their skill and knowledge of drugs to inquire into the surrounding circumstances of the case. In this respect the finding of his lordship in Prendergast that the pharmacist should have noticed that the patient paid for the drugs is noteworthy. If there is any doubt in the pharmacist's mind then the prescription should be checked by the prescribing doctor.

When thousands of prescriptions are being written and dispensed every day it is inevitable that mistakes will creep in. The judgments in Dwyer $v$ Roderick and others and in Prendergast $v$ Sam and Dee Ltd have shown that the courts will take a less than tolerant attitude towards those who make careless but negligent mistakes which result in personal injury and will award sufficient damages accordingly.

\section{1 [1983] 80 Law Society Gazette 3003}

2 The Times 1988; Mar 14:19.

3 As to the morality of such a finding, see Finch J. A costly oversight. New Law fournal 1982;Feb 25:176-7.

\title{
Cost versus benefit in non-surgical management of patients with cancer
}

A working group of cancer physicians, epidemiologists, and health economists met recently to consider the need for medical audit of the treatment of patients with cancer. The meeting was set up with the generous support of the Cancer Research Campaign because its participants believed that such an audit has become urgent, with the number of cancer patients rising (owing to the increase in the proportion of elderly people in the population) and with the resources available being limited. The first step should be the development of guidelines for optimal patient care and use of these resources. The group agreed that two key questions had to be answered:

(1) Is unfettered clinical freedom appropriate in the management of patients with cancer?

(2) Is consensus possible on what is appropriate and inappropriate care for patients with cancer?

On the first issue the group believes that unrestrained clinical freedom is inappropriate for management of patients with cancer as it is for other diseases. It results in wide variations in management without corresponding differences in outcome as measured by benefits to patients. ${ }^{1}$ In the context of cancer care such variations are sometimes harmful to the patient and may also waste resources. In particular, while some investigations clearly influence patient management, other indiscriminate investigations usually contribute solely to the acquisition of data and are both irrelevant and wasteful. Examples include the routine use of skeletal surveys, radionuclide scans, and ultrasound in patients with early asymptomatic breast cancer or the search for disease at other sites in patients with documented metastases. ${ }^{2}$

Several controlled studies have shown that no treatment, less treatment, or shorter or cheaper treatment may sometimes be as good as, or better than, a more expensive option. Examples include one versus ten fractions of palliative radiotherapy for the relief of metastatic bone pain ${ }^{3}$ and a randomised trial of cytotoxic chemotherapy versus symptomatic care only for patients with advanced non-small cell lung cancer (C J Williams et al, paper to 4th European Conference on Cancer and Cancer Nursing, 1987). Similarly it is not easy to justify (other than within the context of clinical research studies) the use of new and expensive cytotoxic or hormonal drugs where clear advantage over older and cheaper agents has not been established in controlled trials.

Whenever possible the optimum management for individual patients should be based on the outcome of carefully planned and well controlled clinical trials, but when such research studies are in apparent conflict or there is controversy about treatment decisions should be assisted by consensus-based guidelines.

Curative treatments may be costly, but they are often proportionally less expensive than palliative treatment when measured in terms of life years gained. ${ }^{4}$ When planning treatment clinicians need to distinguish clearly between those with curative and those with palliative intent; failure to do so may result in complex expensive treatments of unproved benefit being given to patients who would be better off with no treatment or a simpler, cheaper option (S E Vogl et al, paper to 13th International Congress of Chemotherapy, 1983). Failure to distinguish between palliative and curative intent may also lead to diversion of resources from areas where the same expenditure may procure substantially greater benefit for the same or other patients.

All cancer physicians must, we believe, consider not only the medical but also the social and financial consequences of their actions; if we do not recognise this responsibility then non-clinicians will take over decision making on the distribution of resources. For this reason the working group was concerned by the apparent lack of interest of manv physicians in the issue of resource allocation and the apparent inability of clinicians to decide on a consensus for the management of common clinical conditions. The following recommendations were agreed and will form a basis for further action:

(1) Guidelines defining appropriate and inappropriate care in cancer need to be set out by an expert review panel for each tumour site. 
(2) Such consensus statements should be distributed to the medical profession, be made available upon request to all interested bodies, and be reevaluated and updated on a regular basis. The demand on resources of different treatments should be included in these reviews.

(3) Action should be taken to establish consensus panels without delay. This will require the active support of both physicians and those agencies concerned with the delivery of care to patients with cancer.

(4) Savings achieved by rationalisation of cancer management should remain available for reallocation to other areas of cancer care.

1 Wennberg JE, Barnes BA, Zubkoff $M$. Professional uncertainty and the problem of supplier induced demand. Soc Sci Med 1982;16:811-24.

2 Ciatto S, Pacini P, Azzini V, et al. Preoperative staging of primary breast cancer. Cancer 1988;61: 1038-40.

3 Price P, Hoskin PJ, Easton D, Austin D, Palmer SG, Yarnold JR. Prospective randomised trial of single and multifraction radiotherapy schedules in the treatment of painful bony metastases. Radiother Oncol 1986;6:247-55. 4 Rees GJG. Cost-effectiveness on oncology. Lancet 1985;ii: 1405-7.

(Accepted 8.7une 1988)

\title{
Lesson of the Week
}

\section{Scalds of the elderly in residential care}

\author{
L C Bainbridge, $M$ J M Black
}

Temperature controls should be fitted to all baths in residential homes for the elderly and disabled
Department of Plastic and

Reconstructive Surgery,

Newcastle General

Hospital, Newcastle upon

Tyne NE3 4RF

LC Bainbridge, FRCs, senior house officer

M J M Black, FRCs,

consultant plastic surgeon

Correspondence to:

Mr Bainbridge.
Accidents to elderly people living at home are inevitable as they strive to maintain their independence, sometimes in the face of increasing disability. In residential homes such accidents should be less common, though their complete avoidance is incompatible with the philosophy of self help as a means of preserving dignity.

Three avoidable fatal burns of elderly patients in residential homes illustrate the problem facing these institutions. The risk of such accidents and the severity of their consequences may often be reduced by simple means.

\section{Case reports}

Case 1-An 80 year old chronic schizophrenic lady who lived in a psychogeriatric unit presented with scalds of $70 \%$ of her body surface area. She had run a bath for herself using only hot water, and then climbed into it unnoticed by the staff. In view of her age and the extent of the burn she was treated symptomatically. She died four hours later.

Case 2-A 70 year old hypothyroid lady who lived in a local authority home presented with scalds to both buttocks, legs, and back estimated to be $15 \%$ of her body surface area. She had climbed into a bath partly filled with hot water while unattended. She was resuscitated, her hypothyroid state corrected, and the burns initially managed conservatively. Areas of full thickness skin loss were grafted six weeks after the injury. She died two weeks later of bronchopneumonia.

Case 3-A 65 year old man with a dense left hemiplegia who lived in a private nursing home presented with scalds estimated to be $37 \%$ of his body surface area. He had been lowered into a hot bath by two nurses who had not checked the temperature of the water. He was resuscitated and the burns managed conservatively. He developed cardiac failure and died seven days after admission.

\section{Discussion}

These patients all presented to a single regional burns unit in one nine month period. This is not, however, a local problem; between 1979 and 1985, 60 people died in residential care from similar scalds (Office of Population Censuses and Surveys, unpublished observations).
Burns are always serious in elderly people, who are at great risk during the resuscitation (with high volumes of intravenous fluids) and from the long period of immobility, from the increased risk of infection, and from any operations necessary to restore skin cover.

These three scalds were due to failures in the supervision and care necessary for elderly patients. Maintaining adequate supervision of such patients who though confused are often extremely resourceful, depends on many factors. Although adequate numbers of staff are necessary (and these are laid down for private establishments), training is also vitally important to enable the staff to maintain appropriate supervision without totally removing the patients' independence.

A back up safety device should, however, be available to reduce the risk of injury on those occasions when the supervision is inadequate. None of these three scalds would have occurred if the temperature of the bath water had been low enough to avoid burning the skin during the period of immersion. Assuming this to be two to three minutes, the temperature of the hot water would have to be less than $50^{\circ} \mathrm{C} .{ }^{1}$ Hospitals are, however, required to store hot water above $61^{\circ} \mathrm{C}$ in order to remove the risk of infection by Legionella pneumophila. ${ }^{2}$ Water at this temperature will cause a full thickness burn of the skin in four seconds. ${ }^{1}$ The problem may be overcome by fitting a thermostatic temperature control to the hot water tap. A suitable device is the MIRA $20 \mathrm{~K}$ thermostatic $3 / 4$ inch mixing valve for hot and cold water (Walker, Crossweller and Co Ltd, Cheltenham GL52 5EP), the price of which at the time of writing was 1250 . A further simple and cheap safety measure is the fitting of a liquid crystal digital bath thermometer with obvious indication of dangerous temperatures. Such thermometers are available from most chemists costing less than $£ 2$. The use of these two controls in all residential homes for the elderly or disabled is recommended.

1 Moritz AR, Henriques FC Jr. Studies of thermal injury. II The relativ importance of time and surf. Sute causation of cutaneous burns. Am J Pathol 1947;23:695-720.

2 Directorate of Works Operations, Department of Health and Social Security. Health service management, legionnaires disease and hospital water systems. London: DHSS, 1980. (HN $(80) 39$.)

(Accepted 26 May 1988 